\title{
Preparation of Modified Low-Melting Point Polypropylene: Effect of Tacticity for Modification
}

\author{
By Ryo AbURATANI, ${ }^{*}$ Shuji MACHIDA, Harumi NAKASHIMA, and Takenori FUJIMURA
}

Low-melting point polypropylene prepared with metallocene catalysts was modified with maleic anhydride and acrylate monomers. The degree of modification depends on the tacticity of the base polypropylene. Low-melting point polypropylene can be easily modified compared to high isotactic polypropylene. The reason came from the low crystallinity of the lowmelting point polypropylene and the random arrangement of methyl groups. The base polymer molecular weight was almost constant at the low temperature modification condition.

KEY WORDS: Polypropylene / Tacticity / Metallocene Catalyst / Maleic Anhydride / Modification / Functionalization / Radical

Initiator /

Polypropylene is one of the most common materials used in various industrial fields. The material is mainly used in nonpolar systems, but is unsuitable for use with polar materials such as polar polymer, glass, or metal.

To use polypropylene with polar materials, free-radical reactions with unsaturated monomers, such as maleic anhydride or acrylic acid derivatives are often used. ${ }^{1-20}$ Polypropylene is partly polarized by this method, and can be utilized in many products, such as adhesives, ${ }^{19}$ coatings, improvement materials for polar polymers, ${ }^{20}$ master batch ${ }^{21}$ for inorganic materials, and colors. However, the characteristics are limited considering the use of polypropylene from the conventional catalyst system. Isotactic and atactic polypropylene are mainly used for industry, and some fields like adhesives utilize atactic polypropylene for its low melting point and high fluidity. An effective method to change the properties of base polymer over a wide range is to use metallocene catalyst.

Some metallocene catalyst systems are formed using a combination of a co-catalyst and a transition metal compound having a cross-linked structure with two cross-linking groups and offer a characteristic structure. ${ }^{22}$ Homo polypropylene obtained from the catalyst system has middle-range tacticity, and shows a low melting point under $100{ }^{\circ} \mathrm{C}$. The conventional catalyst system can also offer low melting point polypropylene by lowering its tacticity and by copolymerization. However, in this case, low molecular weight polymer and atactic polymer are provided, and often have adverse effect on the mechanical properties of the polymer. These adverse-effect components do not appear in metallocene catalyst systems. This catalyst system gives polypropylene ranging from low-molecular weight to high-molecular weight. Therefore, various application ranges may be expected from metallocene type polypropylene.

This polymer also has non-polar characteristics, and can be modified with unsaturated monomers for wide-range utilization. As this polymer has low melting-point and high solubility, different reaction systems can be used to obtain the modified polypropylene. Especially this polymer is useful for research of modification mechanism. Many papers deal with the modification of isotactic ${ }^{6-14}$ and atactic polypropylene, ${ }^{15-18}$ but tacticity effect is not considered because of the difference of molecular weight. And broad molecular weight distribution and un-uniform tacticty further make difficult to understand the effect of tacticity.

The purpose of this study is to develop a modified system of low melting point polypropylene using a radical initiator, and research the tacticity effect of polypropylene to the modification reaction.

\section{EXPERIMENT}

\section{Polymerization of Propylene by Metallocene Catalyst}

The synthesis of (1,2-dimethylsilylene)(2,1'-dimethylsilylene)-bis(3-trimethyl-silylmethylindenyl) zirconium dichloride (DDBSIZrCl) is reviewed in the paper. ${ }^{22}$

A 10-L stainless steel autoclave was dried by heating, 5-L heptane, 5-mmol triisobutylaluminium, $5 \mathrm{mmol}$ methyl aluminoxane, and $0.005-\mathrm{mmol}$ metallocene catalyst were added under nitrogen atmosphere. Subsequently, hydrogen at 0.03 $\mathrm{MPa}$ was introduced in the autoclave, the resultant mixture was heated to $60^{\circ} \mathrm{C}$ while stirring, and propylene gas was introduced in the autoclave at the total pressure of $0.8 \mathrm{MPa}$.

The polymerization was carried out for $90 \mathrm{~min}$ while constant internal pressure was maintained by supplying propylene gas to the autoclave using a pressure regulator. After polymerization, the resultant contents were taken out of the autoclave and vacuum-dried at $80^{\circ} \mathrm{C}$ to obtain low melting point polypropylene (LMPP).

From NMR analyses, the tacticities were as follows: $[\mathrm{mmmm}] /[\mathrm{mmmr}] /[\mathrm{rmmr}] /[\mathrm{mmrr}] /[\mathrm{mmrm}]+[\mathrm{rrmr}] /[\mathrm{rmrm}] /$ $[\mathrm{rrrr}] /[\mathrm{mrrr}] /[\mathrm{mrrm}], 45.6 / 14.0 / 3.6 / 14.4 / 6.1 / 3.4 / 2.3 / 3.1 / 7.4$ $(\mathrm{mol} \%)$. 
Table I. Preparation of polypropylene by DDBSIZrCl catalyst system

\begin{tabular}{|c|c|c|c|c|}
\hline \multicolumn{2}{|c|}{ Polymerization condition } & \multicolumn{2}{|c|}{ GPC } & \multirow{2}{*}{$\begin{array}{c}\text { Tacticity } \\
{[\mathrm{mmmm}](\mathrm{mol} \%)}\end{array}$} \\
\hline $\mathrm{PH}_{2}(\mathrm{MPa})$ & Temp $\left({ }^{\circ} \mathrm{C}\right)$ & $M_{\mathrm{w}}$ & $M_{\mathrm{w}} / M_{\mathrm{n}}$ & \\
\hline 0.03 & 80 & 160000 & 1.9 & 48 \\
\hline 0.03 & 60 & 320000 & 1.9 & 45 \\
\hline 0.3 & 60 & 73000 & 2.1 & 45 \\
\hline 0.6 & 60 & 32000 & 1.8 & 45 \\
\hline
\end{tabular}

$\mathrm{PH}_{2}$ : amount of hydrogen pressure introduced in the autoclave $M_{\mathrm{w}} \cdot M_{\mathrm{w}} / M_{\mathrm{n}}$ : measured with GPC

[mmmm]: measured with ${ }^{13} \mathrm{C}$ NMR spectrum

Table I shows the polymerization condition and characteristics of LMPP. LMPP with various molecular weight can be prepared by the change of condition. In this molecular weight range, the tacticity is not changed. The tacticity is decided by the metallocene catalyst.

\section{Materials}

Atactic and syndiotactic polypropylene were purchased from Aldrich, while isotactic polypropylene was purchased from Prime Polymer.

Radical initiators, triisobutylaluminium, methyl aluminoxane, hydrogen, and propylene were used as received without further purification. Heptane was used after nitrogen bubbling to reduce water.

\section{Analyses}

GPC analyses were performed at $145^{\circ} \mathrm{C}$ and $1.0 \mathrm{~mL} / \mathrm{min}$. using 1,2,4-trichlorobenzene as solvent. The instrument with column, TOSO GMHHR-H(S)HT, was equipped with a refractive indicator, WATERS $150 \mathrm{C}$.

The tacticities were measured with ${ }^{13} \mathrm{C}$ NMR, JEOL JNMEX400. NMR analyses were performed in a mixture of 1,2,4trichlorobenzene/benzene- $d_{6}(9 / 1)$ at $130^{\circ} \mathrm{C}$. The tacticities were counted from the methyl group reasonance.

The amounts of maleic anhydride (MAH) were calculated from the carbonyl absorbance $\left(1700-1800 \mathrm{~cm}^{-1}\right)$ of IR spectrum of modified polymer hot-press film.

\section{Maleic Anhydride Modification (Solution Method)}

Polypropylene, MAH, and xylene were stored in a $20-\mathrm{mL}$ sealed vessel under nitrogen atmosphere and after raising the temperature, a radical initiator was added to the vessel. After the reaction, the resultant solutions were poured into acetone to remove the residual maleic anhydride. The insoluble parts were filtered off and vacuum dried at $140{ }^{\circ} \mathrm{C}$ to obtain modified polypropylene.

\section{Acrylate Monomer Modification}

Polypropylene, acrylate monomer and xylene were stored in a $20-\mathrm{mL}$ sealed vessel under nitrogen atmosphere and after raising the temperature, a radical initiator was added to the vessel. After reaction, all the polymer was dissolved in toluene, and reprecipitated in acetone.

\section{Maleic Anhydride Modification (Non-solvent Process)}

Non-solvent reaction was performed by Laboplastmill (Toyo Seiki) by attaching a twin screw mixer. Base LMPP $\left(M_{\mathrm{w}} 32000\right.$, [mmmm] $\left.44.6 \mathrm{~mol} \%\right) 40 \mathrm{~g}$, benzoyl peroxide $1.6 \mathrm{~g}$, and maleic anhydride $3.2 \mathrm{~g}$ were stored in the Laboplastmill. The mixture was blended at $80 \mathrm{rpm}$ for $10 \mathrm{~min}$. The products were recovered without any treatment.

\section{RESULTS AND DISCUSSION}

\section{Maleic Anhydride Modification of Polypropylenes of Var- ious Tacticities}

Table II shows the result of MAH modification of various polypropylenes by the solution method. The degree of modification is influenced by the tacticity of base polymer. High isotactic PP is difficult to modify. In contrast, atactic and syndiotactic PP can be modified with comparatively ease. The ease with which atactic PP can be modified is because of its

Table II. Maleic anhydride modification of polypropylene with various tacticities

\begin{tabular}{|c|c|c|c|c|c|c|}
\hline \multicolumn{3}{|c|}{ Base polymer } & \multirow{2}{*}{$\frac{\text { Modification temp. }}{{ }^{\circ} \mathrm{C}}$} & \multirow{2}{*}{$\begin{array}{c}\text { MAH } \\
\text { content } \\
\text { (wt \%) }\end{array}$} & \multirow{2}{*}{$\frac{\text { After modification }}{M_{\mathrm{w}}(\mathrm{GPC})}$} & \multirow{2}{*}{$M_{\mathrm{w}} / M_{\mathrm{n}}$} \\
\hline Property & Tacticity (mol \%) & $M_{\mathrm{w}}(\mathrm{GPC})$ & & & & \\
\hline Isotactic & {$[\mathrm{mmmm}] 96$} & 92000 & 130 & 0.49 & 80000 & 3.69 \\
\hline Low isotactic & {$[\mathrm{mmmm}] 45$} & 73000 & 130 & 1.11 & 70100 & 1.92 \\
\hline Low isotactic & {$[\mathrm{mmmm}] 48$} & 160000 & 130 & 0.74 & 138000 & 2.01 \\
\hline Atactic & {$[\mathrm{mmmm}] 36$} & 35000 & 130 & 2.03 & 32000 & 3.21 \\
\hline Syndiotactic & [rrrr] 93 & 180000 & 130 & 1.60 & 151000 & 3.51 \\
\hline Isotactic & {$[\mathrm{mmmm}] 96$} & 92000 & 166 & 0.25 & 64400 & 3.26 \\
\hline Low isotactic & {$[\mathrm{mmmm}] 45$} & 73000 & 166 & 0.76 & 62500 & 1.83 \\
\hline Low isotactic & {$[\mathrm{mmmm}] 48$} & 160000 & 166 & 1.70 & 121000 & 1.93 \\
\hline Atactic & {$[\mathrm{mmmm}] 36$} & 35000 & 166 & 1.07 & 31800 & 3.06 \\
\hline Syndiotactic & {$[\mathrm{rrrr}] \quad 93$} & 180000 & 166 & 2.28 & 134000 & 2.82 \\
\hline
\end{tabular}

Conditions: Base polymer/radical initiator/maleic anhydride/xylene $/ 4 \mathrm{~g} / 0.16 \mathrm{~g} / 0.32 \mathrm{~g} / 40 \mathrm{~mL}, 30 \mathrm{~min}$

Reaction Temp. $130^{\circ} \mathrm{C}$ : benzoyl peroxide; $166^{\circ} \mathrm{C}$ : di-t-butyl peroxide

$M_{\mathrm{w}} \cdot M_{\mathrm{w}} / M_{\mathrm{n}}$ : measured with GPC

[mmmm]: measured with ${ }^{13} \mathrm{C}$ NMR spectrum

$\mathrm{MAH}$ amount: Calculated from the absorbance of carbonyl group $\left(1700-1800 \mathrm{~cm}^{-1}\right)$ of infrared spectra 


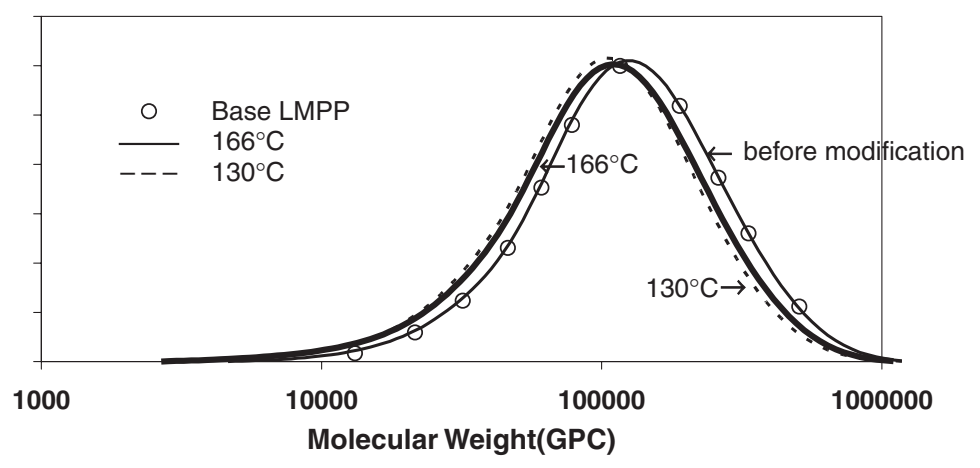

Figure 1. Difference in GPC curves of modified LMPP (base LMPP $M_{\mathrm{w}} 160000$, [mmmm] 48\%).

low molecular weight. The easiness of low molecular weight can observe from the result of LMPP. However LMPP and syndiotactic PP show high MAH amount in spite of high molecular weight.

Like this, LMPP is moderately easy to modify. High modification amount is important for industry, but high temperature is often needed to obtain. High temperature modification reduce molecular weight. Figure 1 shows the
GPC curves of modified and non-modified LMPP. The change of molecular weight is not so large, in case of LMPP, the modification reaction is effectively progressed at low temperature than isotactic PP.

The MAH amounts depend on the stereo-structure of base polymers. The degree of modification is decided by the degree of peroxide attack (eq 2)), MAH addition (eq 3)), and recombination of radical-polymer chain (eq 4)).

1) Initiation

$$
\mathrm{R}-\mathrm{R} \rightarrow 2 \mathrm{R}
$$

2) Radical attack to polymer chain or polymer end group

$$
\text { ex. Polymer }+\mathrm{R} \cdot \rightarrow \text { (Polymer chain) }-\mathrm{CH} 2-\mathrm{C} \cdot-(\text { Polymer Chain })+\mathrm{R}-\mathrm{H}
$$

3) $\mathrm{MAH}$ addition to radical polymer

$$
\begin{aligned}
& \text { ex. (Polymer chain)- } \mathrm{CH}_{2}-\mathrm{C} \cdot-(\text { Polymer Chain })+\mathrm{MAH} \\
& \stackrel{\mathrm{CH}_{3}}{\rightarrow} \quad \text { (Polymer chain) }-\mathrm{CH}_{2}-\mathrm{C}(\mathrm{MAH} \cdot)-(\text { Polymer Chain })
\end{aligned}
$$

4) Recombination

$$
\text { ex. } 2 \text { (Polymer chain)- } \mathrm{CH}_{2}-\mathrm{C} \cdot-(\text { Polymer Chain) } \rightarrow \text { PP Polymer }
$$

Racemic sequence is probably favorable for modification. The reasons are considered to be as follows:

a) Before recombination of radical polymer chain, MAH is effectively added.

b) Radical attack to polymer main chain and/or end group is easy.

From these considerations, the all iso-sequence is blocked on one side by methyl groups. In contrast, the methyl groups of low-tactic and syndiotactic PP do not cooperatively block the attack on polymer chain. Radical initiator and MAH can easily go around the interrupting single methyl group.

Further, isotactic polypropylene is highly crystalline compared to LMPP and syndiotactic PP, and the polymer chain mobility is considered to be low although in solution state. PP and MAH do not dissolve each other. Therefore, after radical attack, radical active polymer chain, as in eq 2 with high crystallinity, may be difficult to come in contact with polar MAH. 


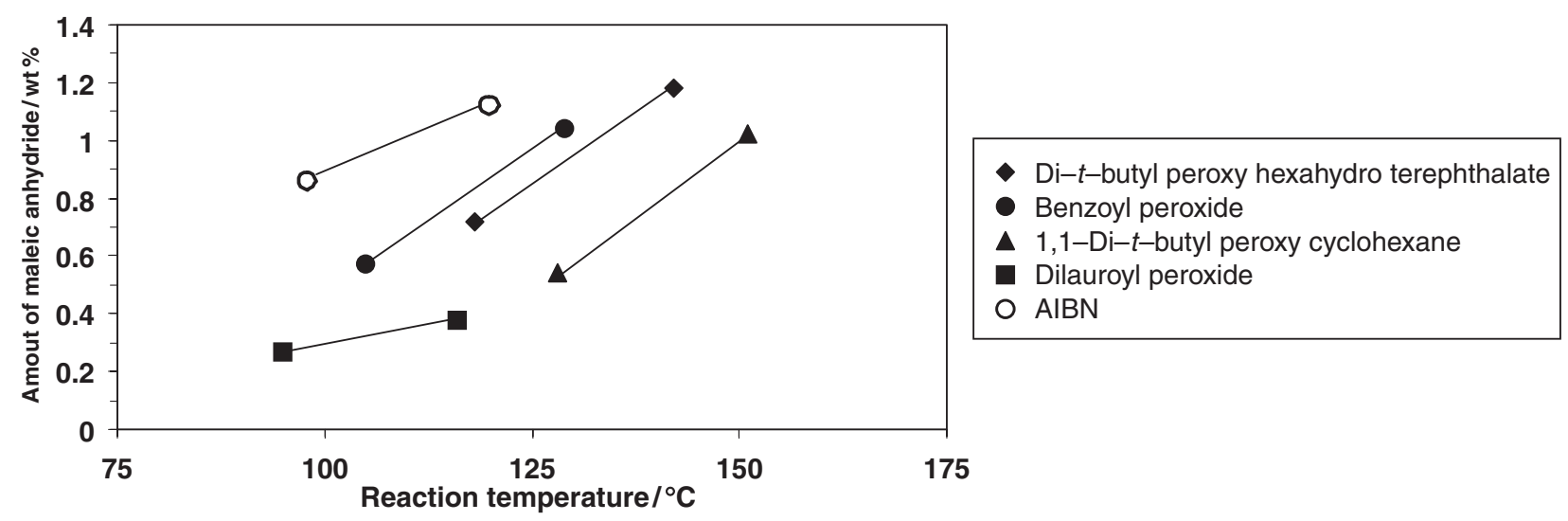

Figure 2. Effect of maleic anhydride modification of low melting point polypropylene on various radical initiators (base LMPP $M_{w} 73000$, [mmmm] 45\%).

From the results above, it is observed that low-tacticity PP can be modified moderately by middle range temperatures. Figure 2 shows the results of MAH modification with various radical initiators. The modification temperatures were decided from the data of degradation of the radical initiators. For each radical initiator, low reaction temperature is $10 \mathrm{~min}$ half-time degradation, and high temperature is $1 \mathrm{~min}$.

The degrees of modification depend on the kind of radical initiators. AIBN is the most effective initiator in this condition. MAH increases when the modification temperature is raised because of the high efficiency of radical attack.

It was observed from the results that LMPP was modified at about $100^{\circ} \mathrm{C}$. This middle range temperature modification is significant for application. This can be applied to various monomers which are not stable at high temperature like acrylate monomer. The amount of undesirable homo polymer, which is not branched on PP, can be controlled.

Table III shows the results of modification of LMPP by esters of methacrylate and acrylate monomers.

The modification amount depends on the conditions and monomers. In the case of glycidyl methacrylate, low temperature increased the modification amount compared to the results of MAH modifications. From the results of MAH modifications, it was concluded that the number of branch points decreased when the modification temperature decreased. From this consideration, low temperature modification will produce long branch polymers with few branch points. Although acryl ester monomer presents the same figures, further detailed structural investigation is necessary.

\section{Maleic-anhydride Modification of LMPP: Non-solvent Process}

Extrusion system is used for preparing maleic anhydride modified polypropylene ${ }^{23}$ for industrial preparation. This system is useful for obtaining low-cost modified polypropylene, but has some disadvantages, such as the residue of unreacted maleic anhydride and radical initiators. The residues can be removed by washing with polar solvent such as acetone, but the additional process increases the cost of the product. It is important to select the proper conditions to modify polypro-
Table III. Modification of LMPP by (meth)acrylate monomers

\begin{tabular}{cccc}
\hline Monomer & $\begin{array}{c}\text { Radical } \\
\text { initiator }\end{array}$ & $\begin{array}{c}\text { Temp. } \\
{ }^{\circ} \mathrm{C}\end{array}$ & $\begin{array}{c}\text { Modification } \\
\text { amount }^{\mathrm{a})} \\
\text { wt } \%^{\circ}\end{array}$ \\
\hline 2-Ethylhexyl acrylate & BPO & 130 & 1.8 \\
$"$ & DTBO & 166 & 1.8 \\
Glycidyl methacrylate & BPO & 130 & $>15 \%$ b) \\
$"$ & DTBO & 166 & 8.6 \\
\hline
\end{tabular}

Modification condition: Base polymer: [mmmm] $45 \mathrm{~mol} \%, M_{\mathrm{W}}$ (GPC) 73000 Base polymer/radical Initiator/monomer/xylene $1 \mathrm{~g} / 0.33 \mathrm{mM} / 1 \mathrm{~g} / 10 \mathrm{~mL}$ 30 min.

BPO: benzoyl peroxide; DTBO: di-t-butyl peroxide

a) Calculated from the absorbance of carbonyl group $\left(1700-1800 \mathrm{~cm}^{-1}\right)$ of infrared spectra

b) The carbonyl absorbance of infrared spectra is out of the fixed quantity

pylene. Fortunately, this LMPP can be applied to lowtemperature decomposition type initiators, and the residue of initiator, which may limit the application of the product only by heat treatment after modification, can be reduced.

For practical application, the non-solvent reaction system (Table IV) was tried out first.

Here, the amounts of maleic anhydride before and after washing with acetone are shown. The tendency against the temperature is the same as observed in Figure 2. High temperature treatment increases the modification amount, and decreases the molecular weight of the polymer. High amount of maleic anhydride is favorable for various applications. In contrast, degradation of polymer often limits the application of the modified polymers. For example, addition of low molecular weight factor decreases the tensile strength of the polymer composite products. Invariant molecular weight condition enables the desired molecular design to be easily obtained. It also enables design of high molecular weight modified polymer, if the molecular weight of the base polymer is high.

Unfortunately, the modification amount for low temperature treatment is low, and the effect of the polar group is limited. Attempts were made to enhance the amount of modification, and to add the $\alpha$-olefin monomer, 1 -decene to the system. 1Decene monomer can co-polymerize with maleic anhydride. 
Table IV. Preparation of maleic-anhydride modified LMPP by batch non-solvent reaction

\begin{tabular}{|c|c|c|c|c|c|}
\hline \multirow{2}{*}{$\begin{array}{l}\text { Temp. } \\
{ }^{\circ} \mathrm{C}\end{array}$} & \multirow{2}{*}{ 1-Decene } & \multicolumn{2}{|c|}{ Modification Amount (wt \%) } & \multicolumn{2}{|c|}{ GPC } \\
\hline & & After reaction & Washed with acetone & $M_{\mathrm{w}}$ & $M_{\mathrm{w}} / M_{\mathrm{n}}$ \\
\hline Before modification & - & - & - & 32000 & 1.97 \\
\hline 100 & none & 1.67 & 0.94 & 32900 & 1.99 \\
\hline 120 & none & 2.76 & 1.35 & 30500 & 2.70 \\
\hline 180 & none & 3.40 & 1.81 & 26000 & 2.28 \\
\hline 100 & $2.8 w t \%$ & 3.40 & 2.22 & 34400 & 2.00 \\
\hline
\end{tabular}

Batch non-solvent reaction was performed by Laboplastmill (Toyo Seiki)

Base polymer/benzoyl peroxide/maleic anhydride 100/4/8(wt/wt/wt)

Reaction conditions $10 \mathrm{~min}$., $100 \mathrm{rpm}$

Base polymer: [mmmm] $45 \mathrm{~mol} \%$

$M_{\mathrm{w}} \cdot M_{\mathrm{w}} / M_{\mathrm{n}}$ : measured with GPC

$\mathrm{MAH}$ amount: Calculated from the absorbance of carbonyl group $\left(1700-1800 \mathrm{~cm}^{-1}\right)$ of infrared spectra

Only MAH modification system

MAH addition to radical polymer

$$
\begin{aligned}
& \text { ex. (Polymer chain)- } \mathrm{CH}_{2}-\mathrm{C} \cdot-(\text { Polymer Chain })+\mathrm{MAH} \\
& 1 \\
& \mathrm{CH}_{3} \\
& \rightarrow \text { (Radical transfer }) \rightarrow \text { (Polymer chain)-C(MAH) -(Polymer Chain) } \\
& \stackrel{\mathrm{C}}{\mathrm{CH}_{3}}
\end{aligned}
$$

MAH and 1-decene modification

$$
\begin{aligned}
& \text { ex. (Polymer chain)-CH - -(Polymer Chain) }+\mathrm{MAH}+1 \text {-Decene } \\
& \stackrel{\mathrm{I}}{\mathrm{CH}_{3}} \\
& \rightarrow \quad \text { (Polymer chain)-C(MAH-Decene } \cdot) \text {-(Polymer Chain) } \\
& \text { I } \\
& \mathrm{CH}_{3}
\end{aligned}
$$$$
\rightarrow(\mathrm{MAH} / 1-\text { Decene copolymerization }) \rightarrow
$$

$$
\rightarrow \rightarrow \text { (Polymer chain)-(block-co-MAH-1-Decene) }
$$

Therefore, the modification sequence differs from the maleic anhydride-only modification system. In case of the maleic anhydride-only system, the maleic anhydride group is arranged as only one unit. In contrast, in the 1-decene used system, maleic anhydride and 1-decene are alternatively arranged with some length. The state of the polar group arrangement is different in the two systems. This $\alpha$-olefin addition is useful for high modification amounts. However, the polar group arrangement may be unfavorable for some applications, this method must be selected for suitable fields.

\section{Maleic-anhydride Modification of LMPP: Continuous Process}

This system was applied to continuous process, twin-screw extruder system. The results are shown in Table V.
To make the resulting polymer in strand shape, higher molecular weight of LMPP than that in the batch process was used. The merits of twin-screw extruder are low cost and the ease in obtaining mass samples. However, this system has disadvantages also; for example, the reaction time is limited in proportion to the amount of the products. In this case, the reaction time of the polymer is about $3 \mathrm{~min}$. In contrast, the half-life of BPO is about $100 \mathrm{~s}$, the reaction time is insufficient. The low value of modification amount may be responsible for the reaction time, but this system can be used to modify LMPP. Further investigations will enable manufacture of more various modified LMPPs.

\section{Applications of Modified LMPP}

Low melting point polypropylene can be modified by maleic 
Table V. Preparation of maleic anhydride modified LMPP by extruder

\begin{tabular}{ccc}
\hline Radical intiator/maleic anhydride & $\begin{array}{c}\text { Modification amount } \\
\text { wt } \%\end{array}$ & $\begin{array}{c}\text { GPC } \\
M_{\mathrm{w}}\end{array}$ \\
\hline $2 \mathrm{wt} \% / 4 \mathrm{wt} \%$ & $1.3 \mathrm{wt} \%$ & 73000 \\
$4 \mathrm{wt} \% / 8 \mathrm{wt} \%$ & $2.1 \mathrm{wt} \%$ & 72000 \\
\hline
\end{tabular}

Extruder: Twin-screw extruder (Toyo Seiki)

Base polymer: $M_{w}(\mathrm{GPC}) 73000,[\mathrm{mmmm}] 45 \mathrm{~mol} \%$

Radical initiator: Benzoyl peroxide; $120^{\circ} \mathrm{C}$; Reaction time: about $3 \mathrm{~min}$.

Modification amount: After reaction without wash with acetone

$M_{\mathrm{w}} \cdot M_{\mathrm{w}} / M_{\mathrm{n}}$ : measured with GPC

MAH amount: Calculated from the absorbance of carbonyl group (1700-

$1800 \mathrm{~cm}^{-1}$ ) of infrared spectra

anhydride and acrylate monomers. This modified polymer has the property of mixing with high tacticity polypropylene and ethylene propylene co-polymer. Therefore, it can be applied to improve polypropylene composites containing glass fiber, talc, and polar polymers. However, LMPP is soft and flexible, so it cannot be used in applications requiring stiffness and hardness.

Low melting point is useful in some applications. For instance, it can be applied to natural polar waxes and polysaccharides which are damaged at high temperature.

Furthermore, this polymer is useful for hot melt adhesives. The soft and flexible properties are suitable for sticking polyolefin and polar materials.

Received: April 23, 2008 Accepted: September 23, 2008 Published: November 12, 2008

\section{REFERENCES}

1. G. Moad, Prog. Polym. Sci., 24, 81 (1999).

2. K. E. Russell, Prog. Polym. Sci., 27, 1007 (2002).

3. M. Rätzch, M. Arnold, E. Borsig, H. Bucka, and N. Reichelt, Prog. Polym. Sci., 27, 1195 (2002).
4. W. Qiu and T. Hirotsu, Macromol. Chem. Phys., 206, 2470 (2005).

5. Z. Wang, H. Hong, and T. Chung, Macromolecules, 38, 8966 (2005).

6. F. Ide and A. Hasegawa, J. Appl. Polym. Sci., 18, 963 (1974).

7. a) P. A. Callais and R. T. Kazmierczak, Annu. Tech. Conf.-Soc. Plast. Eng., 1368 (1989).

b) P. A. Callais and R. T. Kazmierczak, Annu. Tech. Conf.-Soc. Plast. Eng., 1921 (1990).

8. C. C. Chen and J. L. White, Annu. Tech. Conf.-Soc. Plast. Eng., 969 (1991).

9. D. Shi, J. H. Yang, Z. H. Yao, Y. Wang, H. L. Huang, W. Jing, J. H. Yin, and G. Costa, Polymer, 42, 5549 (2001).

10. J. M. García-Martínez, J. Taranco, O. Laguna, and E. P. Collar, Int. Polym. Process., 9, 246 (1994).

11. J. M. García-Martínez, O. Laguna, and E. P. Collar, J. Appl. Polym. Sci., 68, 483 (1998).

12. H. G. Frittz, Q. Cai, and R. Anderlik, Macromol. Symp., 83, 93 (1994).

13. J. E. Bidaux, G. D. Smith, N. Bernet, J. A. E. Manson, and J. Hilborn, Polymer, 37, 1129 (1996).

14. B. de Roover, J. Devaux, and R. Legras, J. Polym. Sci., Part A: Polym. Chem., 34, 1195 (1996).

15. D. Braun, I. Braun, I. Kramer, and G. P. Hellmann, Angew. Makromol. Chem., 251, 37 (1997).

16. E. P. Collar, C. Marco, O. Laguna, S. Areso, and J. M. GarciaMartinez, J. Therm. Anal. Calorim., 58, 541 (1999).

17. J. M. García-Martínez, S. Areso, and E. P. Collar, J. Appl. Polym. Sci., 104, 345 (2007)

18. G. Akm-Öktem, S. Cetin, and Z. Oktem, Polym. Bull., 45, 245 (2000).

19. C. Lin and W. Lee, J. Appl. Polym. Sci., 70, 383 (1998).

20. B. Lu and T. Chung, Macromolecules, 32, 2525 (1999).

21. a) K. Ohkawa and S. Kondo, Jpn. Kokai, Tokkyo Koho, 2002, $2002-$ 20559.

b) M. Nomura, K. Wada, and T. Shima, Jpn. Kokai, Tokkyo Koho, 1999, 11-255987.

22. a) Y. Minami, Idemitsu Gihou, 48, 328 (2005). b) Y. Minami and Y. Mogi, International Patent, WO1999/09098. http://www.idemitsu.co.jp/ipc/chemistry/adhesive/lmpp.html

23. a) S. Kondo and T. Sanada, Jpn. Kokai, Tokkyo Koho, 2004, 2004175909.

b) T. Jyoui, T. Nogata, and T. Nakasato, Jpn. Kokai, Tokkyo Koho, 1995, 7-173229. 